\title{
Antimicrobial Oil-in-Water Nanoemulsions: Synergistic Effect of Nisin and Carvacrol against Bacillus subtilis
}

\author{
Marcos Antonio Neves ${ }^{1,2}$, Porsry Ung ${ }^{1,3}$, Kunihiko Uemura ${ }^{2}$, Chieko Takahashi ${ }^{2}$, Isao Kobayashi ${ }^{2}$, Patrizia \\ Romano $^{4}$ and Mitsutoshi Nakajima ${ }^{1,2}$ \\ 1. Graduate School of Life and Environmental Sciences, Alliance for Research on North Africa, University of Tsukuba, 1-1-1 \\ Tennodai, Tsukuba, Ibaraki 305-8572, Japan
}

2. Food Engineering Division, National Food Research Institute, NARO, 2-1-12 Kannondai, Tsukuba, Ibaraki 305-8642, Japan

3. International Master EDAMUS - Sustainable Management of Food Quality, Univ. of Montpellier, 15 Av. Charles Flahault, B.P. 14491, 34093 Montpellier, France

4. School of Agricultural, Forest, Food and Environmental Sciences (SAFE), University of Basilicata, Via Ateneo Lucano, 10, 85100

Potenza, Italy

\begin{abstract}
The aim of this study was to elucidate the mode of action of two antimicrobial compounds, nisin, which is hydrophilic, and the lipophilic compound carvacrol. For that purpose, both antimicrobials were loaded into Oil-in-/Water nanoemulsions, and their antimicrobial activity against Bacillus subtilis was investigated. The experimental results indicated that the O/W nanoemulsions loaded with both, nisin and carvacrol, having Sauter mean diameter $\left(d_{3,2}\right)$ of around $120 \mathrm{~nm}$, were considerably stable under the conditions investigated (up to 1 week storage at room temperature). The interfacial tension between nisin aqueous solutions and soybean oil could be reduced up to $12 \mathrm{mN} / \mathrm{m}$, as compared to that of pure water and soybean oil $(21 \mathrm{mN} / \mathrm{m})$, so that demonstrating the potential of nisin to be used as emulsifier. The results obtained for $\mathrm{O} / \mathrm{W}$ nanoemulsions loaded with both antimicrobial compounds indicated a reduction of nearly two log cycles (around 100 times) on B. subtilis population upon incubation for $24 \mathrm{~h}$, compared to the blank (10 $\mathrm{mM}$ phosphate buffer).
\end{abstract}

Key words: Antimicrobial, nanoemulsion, nisin, carvacrol, synergy, Bacillus spp.

\section{Introduction}

Amidst nowadays-busy life styles, food products are major players while maintaining human health and asides from satiating human hunger. Moreover food-borne diseases and microbial contamination represent a major concern in nowadays world, whereas the consumption of fresh foods such as horticultural products, seafood, and meat has been increasing steadily, due to the need of consumers for convenient ready-to-eat or ready-to-cook foods, along with their desire to have a healthy lifestyle. The food involved is usually contaminated by pathogen/toxigenic microorganisms or toxicants,

Corresponding author: Marcos Antonio Neves, assistant professor, research field: advanced food processing, functional foods. which may cause illnesses. In the same way, some microorganisms may not be harmful for human health, but they can cause food spoilage by producing undesirable compounds [1].

Foreseeing the prolonged shelf life of fresh agricultural products, with minimum degradation of their nutritional quality post-processing, edible films and coatings have increasingly received a great deal of attention in recent years, considering their advantages over synthetic. For instance nanocomposite films based on different ratios of chitosan and nanoclay were formed and characterized, aiming to enhance the vapor barrier and mechanical properties of the nanocomposite films formed, foreseeing their potential application into smart food packaging systems [2]. In fact, active antimicrobial packaging is 
one of the innovative food packaging concepts that have been introduced as a response to the continuous changes in current consumer demands and market trends [3].

Aside from strategies involving the external packaging, at present, a wide variety of chemical preservatives are permitted for direct use into foods to prevent the growth of food spoilage and disease causing bacteria. The type of preservative, amount allowed to be used and in which foods vary between countries but use of preservatives is increasingly being negatively perceived by consumers [4]. On the one hand, the use of plant antimicrobials fulfils the needs of today's consumer looking for wholesome food without chemical preservatives. Nevertheless, the antimicrobial activity of plant extracts observed in vitro conditions is different from its effect in complex food systems. In most cases, antimicrobial activity decreases due to interactions with food components. On the other hand, essential oils comprise a large number of components, and their mode of action is likely involved with several targets in the bacterial cell. Their hydrophobicity enables them to partition in the lipids of the cell membrane and mitochondria, rendering them permeable and leading to leakage of cell contents. In other words, carvacrol has exhibited a high antimicrobial activity compared to other essential oils [5], and the synergism between carvacrol and its precursor p-cymene has been reported [6].

Among the different classes of antimicrobials often used in food industry, bacteriocins represent an attractive choice with regard to consumers demanding natural and healthier products, avoiding the use of chemical preservatives. Bacteriocins are antimicrobial peptides produced by bacteria and can kill or inhibit the growth of other bacteria (usually closely related species) [7]. Among them, nisin is the most representative antimicrobial peptide, and due to its potential activity, it has been applied in food industries since the mid-1940s [8], especially to dairy products for inhibiting the growth of Gram-positive bacteria [9]. Nisin has been approved by Food and Drug Administration (FDA) and World Health Organization (WHO) for the use as a generally recognized as safe (GRAS) food additive. Nisin is a low molecular weight polypeptide composed of 34 amino acids, schematically represented in Fig. 1 [10]. Further developments of nisin are likely to include synergistic action of nisin with chelators and other bacteriocins, and its use as an adjunct in novel food processing technology such as higher pressure sterilization and electroporation [4].

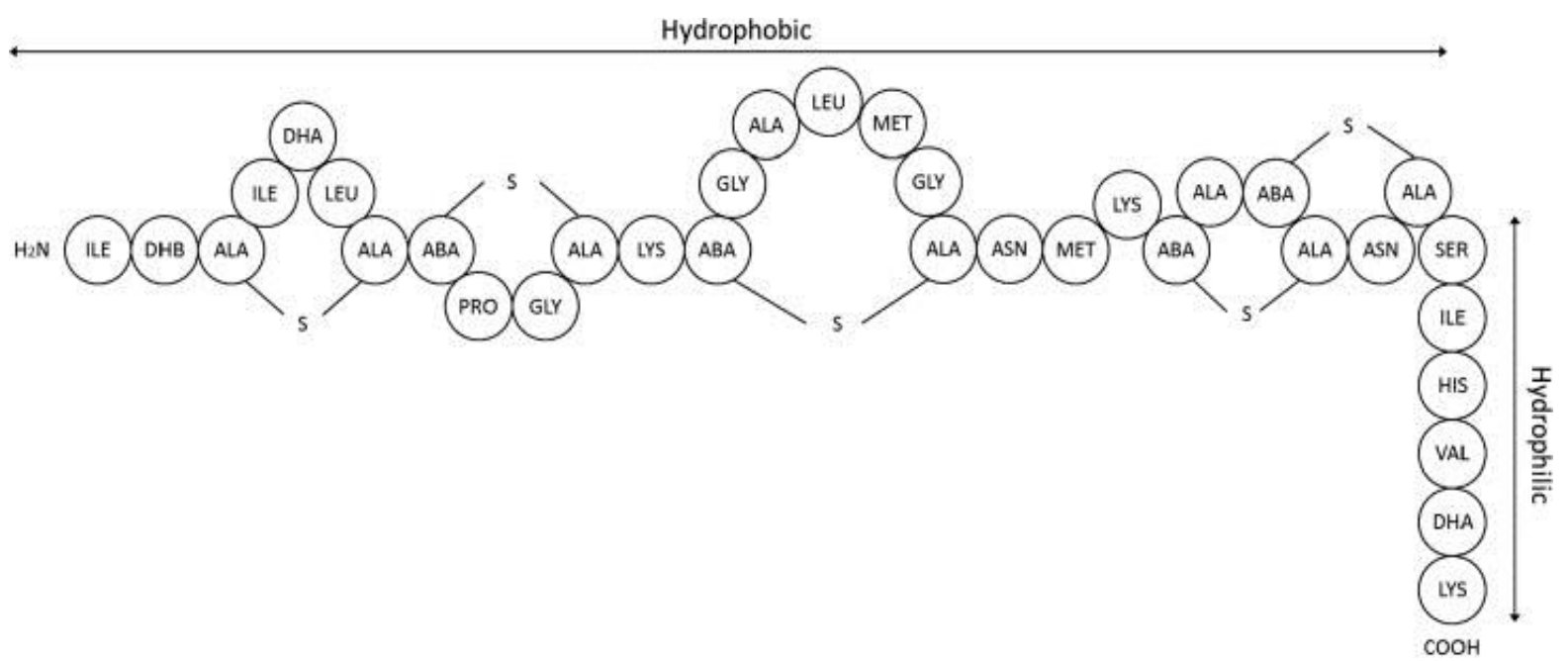

Fig. 1 Scheme representing the chemical structure of nisin, composed of amino acid units distributed along the hydrophilic and hydrophobic sides. The structure is composed of hydrophobic and hydrophilic parts, divided into N-terminal and C-terminal, and five lanthionine rings: Amino acids: Dha, dehydro-alanine; Dhb, dehydrobutyrine; Ala-S-Ala, lanthionine; Abu-S-Ala, $\beta$-methyl-lanthionine (adapted from Refs. [7, 18]). 
Nevertheless, the application of nisin into food industry is still limited somehow, owing to the fact that the above-mentioned bactericidal activities attributed to nisin may be affected when exposed to different environmental factors such as $\mathrm{pH}$ and ionic strength of the food product, aside from the processing and storage temperature, and the food matrix itself, as we have reported in our preliminary studies $[10,11]$.

In recent years different strategies have been investigated, aiming to enhance the stability and efficacy of those compounds towards inhibition of microbial growth. To that end, encapsulation is one of the strategies often used to protect such sensitive substances within the capsule, physically isolated it from the external environment. This barrier can provide protection against various agents, such as oxygen, water, and light, allows for a controlled release of the substance, and prevents contact with other components in a mixture [12]. Among various techniques available for encapsulating natural compounds, emulsification has been proved as an effective method to increase their stability and absorption. The authors have been conducting various studies relating to the emulsification of natural bioactives, depicting the multitude of possibilities, whether encapsulating hydrophobic or hydrophilic molecules [2, 13-15]. In particular, for preparing Oil-in-Water $(\mathrm{O} / \mathrm{W})$ emulsions, initially the lipophilic compounds are dissolved in an oil phase, and subsequently emulsified with an aqueous phase containing an emulsifier to stabilize the oil droplets. Such substances in the form of fine droplets have a better water dispersibility compared to those in bulk form [16].

As described above, the formulation of emulsions has been extensively studied. Nevertheless, up-to-date the authors are not aware of scientific reports dealing with the joint effect of different antimicrobial compounds, specifically the combination of hydrophilic and hydrophobic antimicrobials, incorporating them into nanoemulsions, especially focusing on their synergistic effect. Therefore, the aim of this study was to carry out a systematic study of the formulation of $\mathrm{O} / \mathrm{W}$ nanoemulsions loaded with two different compounds, the hydrophilic antimicrobial nisin, and the lipophilic antimicrobial carvacrol. The efficacy of those $\mathrm{O} / \mathrm{W}$ nanoemulsions against $B$. subtilis, a Gram-positive bacterium, was investigated by loading those antimicrobials separately or in combination while preparing the nanoemulsions, aiming to elucidate the mechanism of their synergistic effect, if any, towards enhanced antimicrobial activity for potential application into food emulsions.

\section{Materials and Methods}

\subsection{Materials}

Nisin produced by strain Lactococcus lactis (product code N5764), was purchased from Sigma Aldrich Co. (Denmark); this product has nearly 2.5 $\mathrm{wt} \%$ purity, balanced by the remaining composition sodium chloride and denatured milk solids (according to the manufacturer).

Carvacrol (Isothymol; product code 030-08521; purity $95 \mathrm{wt} \%$ ) was purchased from Wako Pure Chem. Ind., Ltd. (Tokyo).

Other reagents: Soybean oil, sodium dihydrogen phosphate dihydrate $\left(\mathrm{NaH}_{2} \mathrm{PO}_{4} \cdot 2 \mathrm{H}_{2} \mathrm{O}\right)$, sodium hydrogen phosphate12-water $\left(\mathrm{Na}_{2} \mathrm{HPO}_{4} \cdot 12 \mathrm{H}_{2} \mathrm{O}\right)$, $\mathrm{NaCl}, \mathrm{HCl}(1 \mathrm{~N}), \mathrm{NaCl}(1 \mathrm{~N})$, Polyoxyethylene (20) sorbitan monooleate (Tween 80 ) were all of reagent grade and manufactured by Wako Pure Chem. Ind. Ltd. (Tokyo). Ultrapure Milli-Q water (resistivity 18.2 $\mathrm{M} \Omega \cdot \mathrm{cm}$; Millipore Corp., Bedford, Massachusetts) was used to prepare all aqueous stock solutions.

Cell line and Culture Media: Bacillus subtilis subsp. spizizenii JCM 2499 (Japan Collection of Microorganisms) [17] was kindly provided by the National Food Research Institute (NFRI, Japan). Nutrient agar (product code 05514) and nutrient broth (product code 05511), both manufactured by Nissui Pharm. Co. (Tokyo), were used as substrates for microbial growth. Sterilized Ringer's solution (product 
code 391-01421; $\mathrm{NaCl} 2.25 \mathrm{~g} / \mathrm{L}, \mathrm{KCl} 0.105 \mathrm{~g} / \mathrm{L}$, $\mathrm{CaCl}_{2} \cdot 2 \mathrm{H}_{2} \mathrm{O} 0.16 \mathrm{~g} / \mathrm{L}$; Nihon Seiyaku Co., Tokyo) was used as physiological salt solution for serial dilution of pre-culture media for B. subtilis spores or vegetative cells.

\subsection{Methods}

\subsubsection{Interfacial Tension Measurement}

In order to elucidate the potential interfacial activity of nisin [18] when incorporated to oil-water systems, the interfacial tension between nisin aqueous solutions and soybean oil was measured adopting the pendant drop method [19]. In brief, the shape of a drop of liquid formed at the tip of a syringe can be determined from the balance of forces, which include the interfacial tension between the two immiscible liquid phases, and the gravitational acceleration. For this purpose, serial dilutions of commercial nisin (from 0 to $20 \mathrm{mg} / \mathrm{mL}$ ) were prepared using $10 \mathrm{mM}$ sodium phosphate buffer ( $\mathrm{pH} 6$ ) and kept stirring overnight, to ensure that nisin was completely dissolved prior to measurements. Initially, the density of nisin aqueous solutions, and that of soybean oil were measured using a portable specific gravity meter (DA130N, Kyoto Electronics Manufacturing Co. Ltd., Tokyo). Then, the interfacial tension at water-oil interfaces was then measured using an automatic interfacial tensiometer (PD-W, Kyowa Interface Science Co., Saitama, Japan). The software FAMAS was used in this study. All the measurements were conducted at $25^{\circ} \mathrm{C}$ using the same apparatus and protocol for measurement; the experimental data expressed in $\mathrm{mN} / \mathrm{m}$ are shown here as mean values \pm S.D. ( $\mathrm{n}=10$ repetitions).

2.2.2 Preparation of Antimicrobial Oil-in-Water $(\mathrm{O} / \mathrm{W})$ Nanoemulsions

The dispersed phase consisted of soybean oil alone, or containing carvacrol $(1.5 \mathrm{mg} / \mathrm{mL})$. The continuous aqueous phase consisted of a mixture containing 1 $\mathrm{mg} / \mathrm{mL}$ of commercial nisin dissolved in buffer solution (10 mM sodium phosphate buffer, $\mathrm{pH}$ 6), to assure complete solubilization, containing $2 \mathrm{wt} \%$ of
Tween 80 , as emulsifier to stabilize the $\mathrm{O} / \mathrm{W}$ nanoemulsions. Sodium phosphate buffer was prepared by dissolving $1.38 \mathrm{~g} \mathrm{Na}_{2} \mathrm{HPO}_{4} \cdot 12 \mathrm{H}_{2} \mathrm{O}$ and $2.68 \mathrm{~g} \mathrm{NaH}_{2} \mathrm{PO}_{4} \cdot 2 \mathrm{H}_{2} \mathrm{O}$ and completed up to $1 \mathrm{~L}$ with Milli-Q water, while adjusting the $\mathrm{pH}$ to 6 ; this buffer solution was stored at $4{ }^{\circ} \mathrm{C}$ up to 1 week. Pre-mixtures containing oil-to-water weight ratio of 1:9 were used in all experiments. The $\mathrm{O} / \mathrm{W}$ nanoemulsions were prepared using the two-step emulsification process (represented schematically in Fig. 2), at room temperature. Initially, coarse $\mathrm{O} / \mathrm{W}$ emulsions were prepared using a rotor-stator homogenizer (Polytron PT-3100, Kinematica, Switzerland) at 7,000 rpm for 5 min. Next, fine $\mathrm{O} / \mathrm{W}$ nanoemulsions were prepared by high-pressure homogenization (NanoVater NV200, Yoshida Kikai, Japan) at $100 \mathrm{MPa}, 3$ cycles. Upon formulation, the samples were immediately used for physicochemical characterization or microbiological tests. In order to evaluate the physical stability of the samples prepared, the antimicrobial-loaded $\mathrm{O} / \mathrm{W}$ nanoemulsions were exposed to different thermal treatments (by incubating them in water bath with temperatures controlled between $30{ }^{\circ} \mathrm{C}$ and $90{ }^{\circ} \mathrm{C}$, for $30 \mathrm{~min}$ ) and stored at room temperature up to 1 week, for investigating the emulsion stability.

2.2.3 Mean Droplet Size and Size Distribution of Antimicrobial O/W Nanoemulsions

The analyses for droplet size and size distribution of the $\mathrm{O} / \mathrm{W}$ nanoemulsions were performed using a laser diffraction particle size analyzer equipped with polarization intensity differential scattering (PIDS) technology (LS 13320, Beckman-Coulter, Inc., Miami, FL, USA), which has a particle size measurement range from 0.4 to $2,000 \mathrm{~m}$. The mean droplet size was determined by the surface-weighted mean diameter, so-called Sauter mean diameter $\left(d_{3,2}\right)$, as indicated in Eq. (1):

$$
d_{3,2}=\frac{\text { Volume }}{\text { Surface Area }}=\frac{\sum n_{i} d_{i}{ }^{3}}{\sum n_{i} d_{i}{ }^{2}}
$$

where $n_{\mathrm{i}}$ is the number of droplets, and $d_{\mathrm{i}}$ is the droplet diameter. 


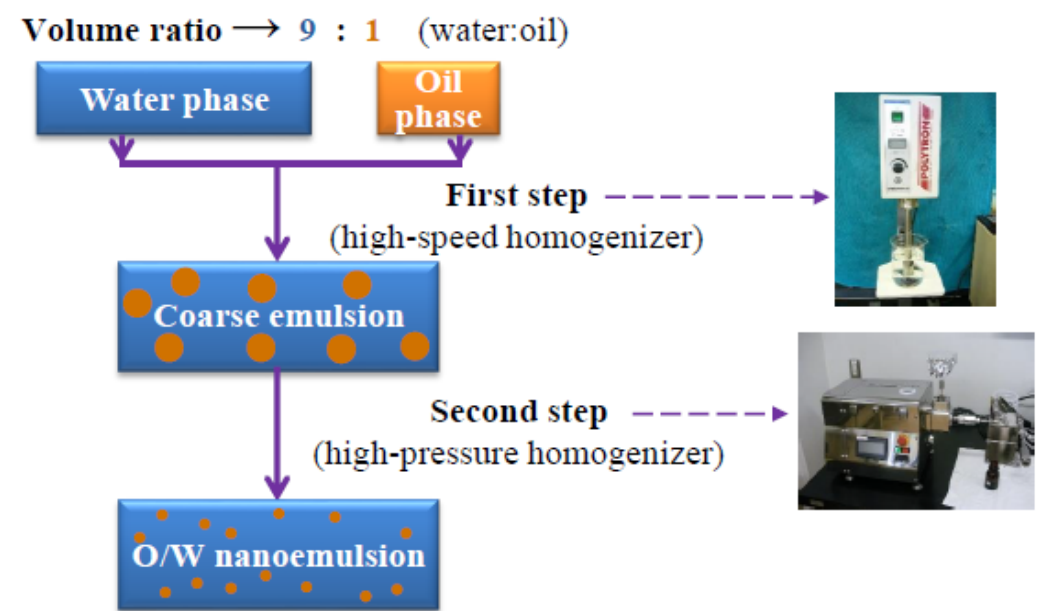

Fig. 2 Illustration of the two-step emulsification process, initially producing coarse $O / W$ emulsions using a high-speed homogenizer, followed by high-pressure homogenization to formulate $\mathrm{O} / \mathrm{W}$ nanoemulsions.

The refractive index (RI) values used to calculate $d_{3,2}$ were 1.42 and 1.33 for soybean oil and water, respectively. All measurements were conducted at $25{ }^{\circ} \mathrm{C}$ in triplicate.

2.2.4 Evaluation of the Antimicrobial Activity of $\mathrm{O} / \mathrm{W}$ Nanoemulsions

In order to investigate the antimicrobial activity of $\mathrm{O} / \mathrm{W}$ nanoemulsions loaded with one of the preservatives or to both simultaneously, B. subtilis was exposed to the following five treatments, separately: (1) Blank (phosphate buffer); (2) Nisin in aqueous solution (N/A); (3) Nisin in $\mathrm{O} / \mathrm{W}$ emulsion (N/E); (4) Carvacrol in O/W emulsion (C/E); (5) Nisin combined with carvacrol in $\mathrm{O} / \mathrm{W}$ emulsion $(\mathrm{N}+\mathrm{C} / \mathrm{E})$. Sodium phosphate buffer ( $\mathrm{pH}$ 6) was used as the blank, and as the continuous phase to formulate $\mathrm{O} / \mathrm{W}$ emulsions containing either $1 \mathrm{mg} / \mathrm{mL}$ of commercial nisin (dissolved in the continuous aqueous phase), 1.5 $\mathrm{mg} / \mathrm{mL}$ of carvacrol (dissolved in soybean oil, and used as disperse phase), or both antimicrobials simultaneously (same concentrations, dissolved in the aqueous and lipid phase, respectively). All the $\mathrm{O} / \mathrm{W}$ emulsions loaded with antimicrobials were formulated according to the procedure indicated above.

In the present study, Bacillus subtilis JCM 2499 spores were used as antimicrobial indicator strain. The bacterial strain was refreshed in the nutrient broth liquid media, and the bacterial spore concentration was adjusted to $10^{9} \mathrm{CFU} / \mathrm{mL}$ and stored at $-80{ }^{\circ} \mathrm{C}$ prior to use. Serial dilutions (from $10^{9} \mathrm{CFU} / \mathrm{mL}$ to $10^{5}$ $\mathrm{CFU} / \mathrm{mL}$ ) were prepared using Ringer's solution or physiological salt solution. The modified pour plate technique procedure used to test the antimicrobial activity against Bacillus subtilis is indicated in Fig. 3; in this method a thin top layer of agar in poured over the microbial cells/antimicrobial emulsion after inoculation, in order to support still colonies' growth for automatic counting. The method used is briefly described next: nutrient agar was melted and cooled to $50{ }^{\circ} \mathrm{C}$, and then nearly $20 \mathrm{~mL}$ of agar were poured onto the empty Petri dishes and let solidify. This was use as the bottom layer of the agar plate. One $\mathrm{mL}$ of bacterial spore suspension $\left(10^{5} \mathrm{CFU} / \mathrm{mL}\right)$ was mixed with $1 \mathrm{~mL}$ of antimicrobial emulsion sample and stirred for $30 \mathrm{~min}$. After $30 \mathrm{~min}$ magnetic stirring, 100 $\mu \mathrm{L}$ of the mixture was spread on top of the solidified nutrient agar, and then another thin layer of agar was poured over the mixture inoculated onto the bottom plate agar, and let solidify. B. subtilis was exposed to one of the preservatives, or to both simultaneously, and the viable count was monitored upon incubation at $37{ }^{\circ} \mathrm{C}$ up to $24 \mathrm{~h}$, using a digital microscope culturing system (S-12, BiomaticTM, DCMS, Miocrobio Co., Japan). All microbiological experiments were performed in triplicate, in a clean bench at room temperature. 


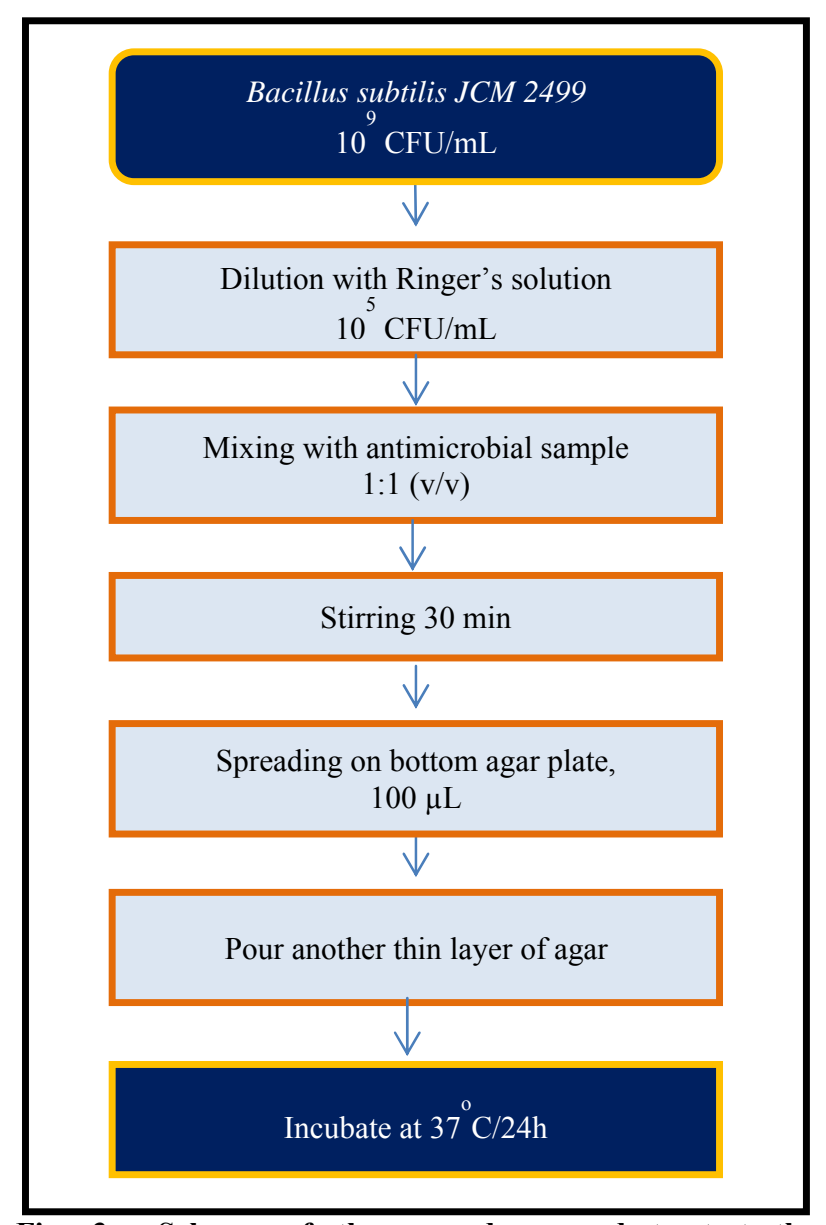

Fig. 3 Scheme of the procedure used to test the antimicrobial activity against Bacillus subtilis, using the modified pour plate technique, which includes pouring a thin top layer of agar over the spores or vegetative cells upon inoculation, in order to support still colonies' growth for automatic counting.

\section{Results and Discussion}

\subsection{Characterization of the Interfacial Activity of Nisin}

Interfacial tension is one of the most important physical properties of the interface between two immiscible fluids. It has been theoretically and experimentally demonstrated that the interfacial tension depends on the partitioning of emulsifiers between the bulk phases and the interface. Therefore, considering that nisin molecule is composed of different amino acid units having both hydrophobic and hydrophilic sides (as indicated in Fig. 1), the interfacial tension between nisin aqueous solutions and soybean oil was measured aiming to elucidate the interface characteristics of nisin, which could be possibly located at the interface between oil droplets and water phase.

The results obtained for interfacial tension between different concentrations of nisin in aqueous solutions (containing from 0 to $20 \mathrm{mg} / \mathrm{mL}$ of commercial nisin) and soybean oil are indicated in Fig. 4. Upon increasing nisin concentration, the interfacial tension decreased gradually from $21 \mathrm{mN} / \mathrm{m}$ to $12 \mathrm{mN} / \mathrm{m}$. Large decrease of interfacial tension was observed from $1 \mathrm{mg} / \mathrm{mL}$ to $10 \mathrm{mg} / \mathrm{mL}$. Thereafter, small decreases on interfacial tension were observed. The interfacial tension remained nearly unchanged at nisin concentration higher than $15 \mathrm{mg} / \mathrm{mL}$. In addition, our results indicated that the interfacial tension between nisin (aqueous solution $20 \mathrm{mg} / \mathrm{mL}$ of commercial nisin) and soybean oil could be reduced up to nearly $12 \mathrm{mN} / \mathrm{m}$, which is considerably lower than the interfacial tension between pure water and soybean oil (21 $\mathrm{mN} / \mathrm{m}$, as indicated by the data for nisin concentration $0 \mathrm{mg} / \mathrm{mL}$, in Fig. 4). Equally important, we have found a critical micelle concentration (CMC) of around $1 \mathrm{mg}$ nisin/mL, as indicated in Fig. 4. At nisin concentration of nearly $10 \mathrm{mg} / \mathrm{mL}$ and thereafter slight decreases on interfacial tension between the nisin aqueous solution and soybean oil were observed, indicating that at this concentration range nisin already has a considerable emulsifying activity, which is in good agreement with the previous literature [18]. The emulsifying ability of nisin has been previously reported, by measuring its ability to stabilize oil droplets in water, using electrical conductivity and image analysis. In that study, the emulsifier capacity of nisin was explained by the amphiphilic characteristic of this molecule, by the absorption into oil and aqueous phase. Nisin showed a significant emulsifying capacity at the concentration of $10 \mathrm{mg}$ nisin/mL, as compared to Tween 80 and $\beta$-casein [18]. However, apparently the antimicrobial activity of nisin is $\mathrm{pH}$-dependent [20]. 


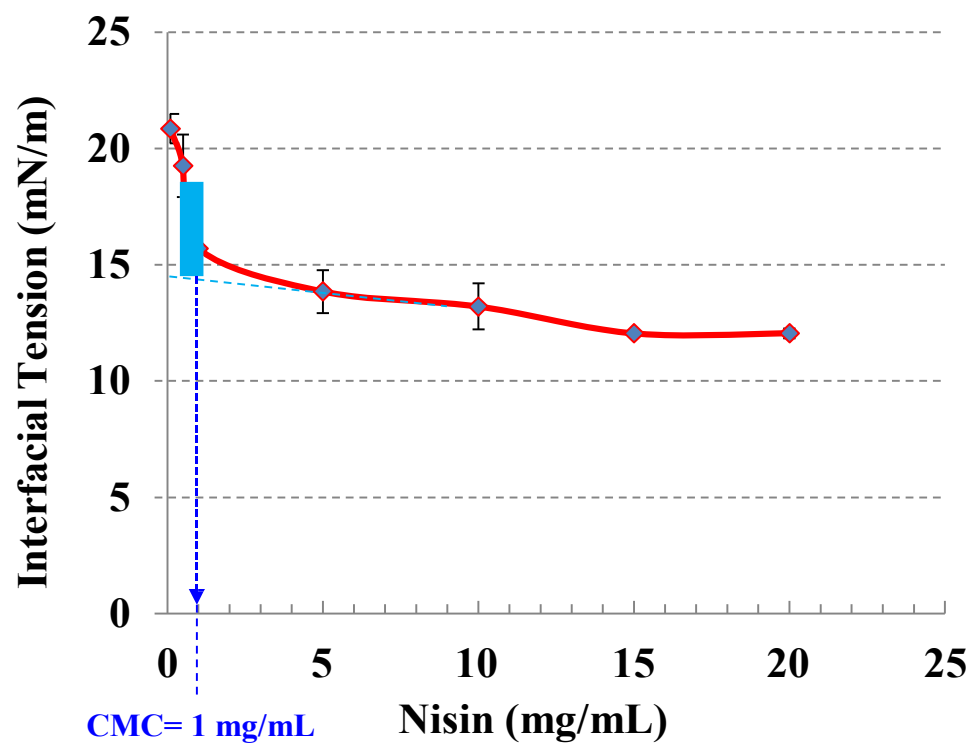

Fig. 4 Interfacial tension between nisin in aqueous solution (from $0 \mathrm{mg}$ to $20 \mathrm{mg} \mathrm{nisin} / \mathrm{mL}$ ) and soybean oil. The critical micelle concentration (CMC) for nisin was nearly $1 \mathrm{mg} \mathrm{nisin} / \mathrm{mL}$.

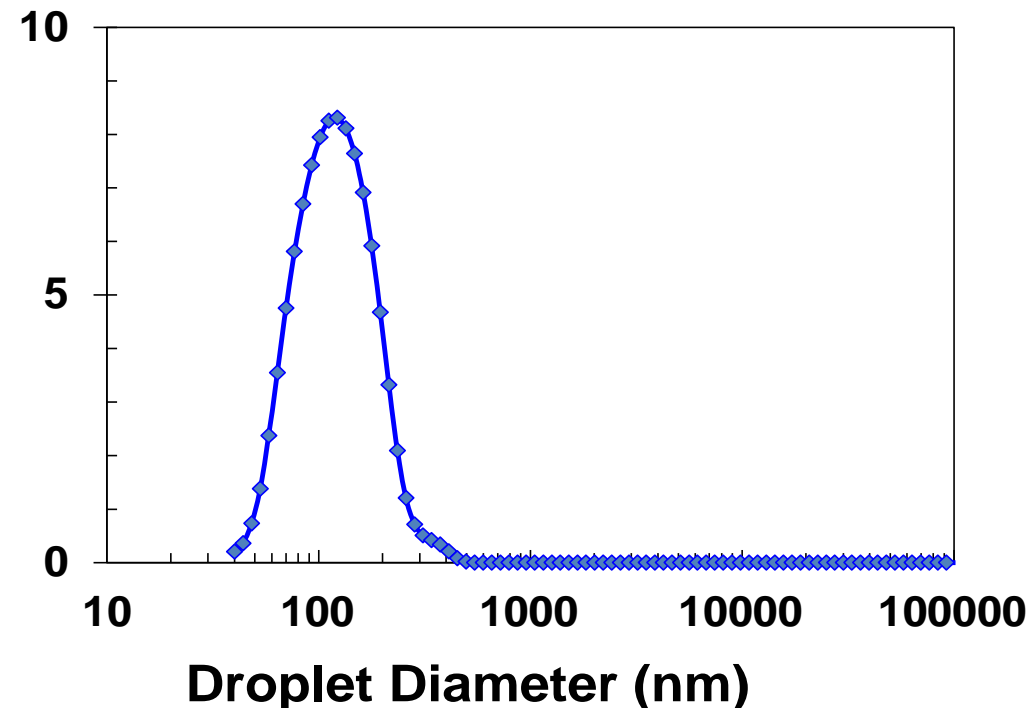

Fig. 5 Droplet size distribution of freshly prepared $\mathrm{O} / \mathrm{W}$ nanoemulsion loaded with both antimicrobial compounds, nisin (1 $\mathrm{mg} / \mathrm{mL}$ ) and carvacrol $(1.5 \mathrm{mg} / \mathrm{mL})$, stabilized by Tween $80(2 \mathrm{wt} \%)$. This sample was formulated using the two-step emulsification process, consisting of high-speed homogenization followed by high-pressure homogenization.

\subsection{Droplet Size and Size Distribution of} Antimicrobial O/W Nanoemulsions

As depicted in Fig. 5, in case of $\mathrm{O} / \mathrm{W}$ nanoemulsions loaded with both antimicrobial compounds $(1 \mathrm{mg} / \mathrm{mL}$ commercial nisin dissolved in the continuous aqueous phase, and $1.5 \mathrm{mg} / \mathrm{mL}$ carvacrol dissolved in the disperse lipid phase) the Sauter diameter $\left(d_{3,2}\right)$ was around $115 \mathrm{~nm}$. Regardless of the $\mathrm{O} / \mathrm{W}$ nanoemulsion composition, whether if contained only nisin in the continuous phase, carvacrol in the disperse phase, or both compounds simultaneously), the experimental results indicated that the $\mathrm{O} / \mathrm{W}$ nanoemulsions were stable, exhibiting no change in mean droplet diameter and no visible evidence of creaming, during one week storage at room temperature. To this end, Tween 80 , a nonionic surfactant, may have been responsible for this considerable high emulsion stability, due to the polymeric group of their head [21]. 
Considering that storage at high temperatures may affect the emulsion viscosity (and thereof possibly causing physical instability) and the interfacial tension in the case of nonionic surfactants [22], and foreseeing the application of the antimicrobial-loaded $\mathrm{O} / \mathrm{W}$ emulsions to different sectors of food industry, the authors investigated the physical stability of $\mathrm{O} / \mathrm{W}$ emulsions stabilized by Tween $80(2 \mathrm{wt} \%)$ upon different thermal treatments (incubation at temperatures between $30{ }^{\circ} \mathrm{C}$ and $90{ }^{\circ} \mathrm{C}$, for $30 \mathrm{~min}$ ), followed by storage at room temperature up to 1 week. The emulsions stability was evaluated by monitoring the mean droplet size. Our results (depicted in Fig. 6) indicated that the mean droplet size $\left(d_{3,2}\right)$ of antimicrobial-loaded $\mathrm{O} / \mathrm{W}$ nanoemulsions thermally treated up to $50{ }^{\circ} \mathrm{C}$ for $30 \mathrm{~min}$ were considerably stable, around $120 \mathrm{~nm}$, even after 1 week storage at room temperature. In case of samples treated either at $60{ }^{\circ} \mathrm{C}$ or $70{ }^{\circ} \mathrm{C}$ for $30 \mathrm{~min}, d_{3,2}$ rapidly increase to nearly double the initial size (reaching around $400 \mathrm{~nm}$ ) upon 1 day storage, but remained stable thereafter, up to 1 week storage. However, at this temperature range, some droplet flocculation was observed. These changes may be explained by the dehydration phenomenon of non-ionic surfactants in the interface of oil and water [22]. Expectedly, in case of samples treated at $80{ }^{\circ} \mathrm{C}$ or $90{ }^{\circ} \mathrm{C}$ for $30 \mathrm{~min}, d_{3,2}$ increased continuously throughout the storage time investigated, and phase separation was also observed.

\subsection{Antimicrobial Activity of O/W Nanoemulsions}

In this work, the following five treatments were used separately to test the antimicrobial activity against B. subtilis: (1) Blank; (2) Nisin in aqueous solution (N/A); (3) Nisin in emulsion (N/E); (4) Carvacrol in emulsion (C/E); (5) Nisin and carvacrol in emulsion $(\mathrm{N}+\mathrm{C} / \mathrm{E})$. The results obtained for $B$. subtilis growth (depicted in Fig. 6) indicated an extension on the lag period, in case nisin whether it was in aqueous solution, or loaded into $\mathrm{O} / \mathrm{W}$ nanoemulsion, especially when both compounds nisin and carvacrol were combined into the same formulation. These results are in agreement with previous literature, whereas nisin antimicrobial activity has been reported to limit or prevent microbial growth by extending the lag period and reducing the growth rate or decrease live counts of microorganism $[23,24]$.

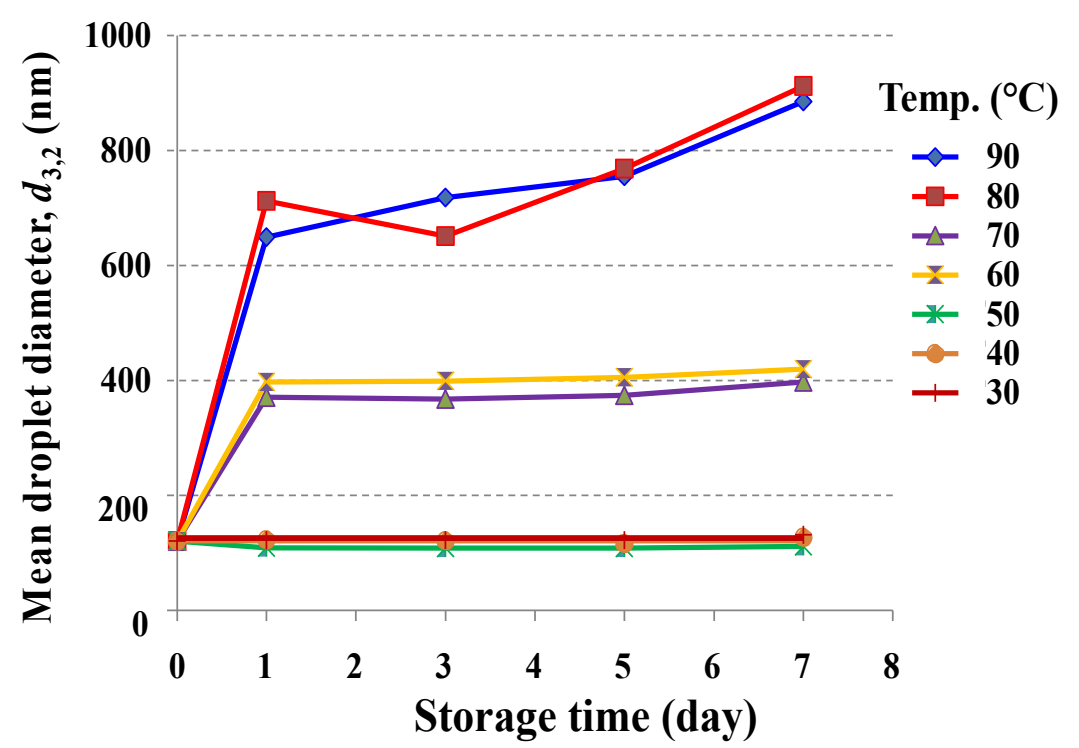

Fig. 6 Thermal stability of antimicrobial $\mathrm{O} / \mathrm{W}$ nanoemulsions: Effect of thermal treatment $\left(30{ }^{\circ} \mathrm{C}\right.$ to $90{ }^{\circ} \mathrm{C}$ for $\left.30 \mathrm{~min}\right)$ on mean droplet size $\left(d_{3,2}\right)$, upon storage up to 7 days, at room temperature. 


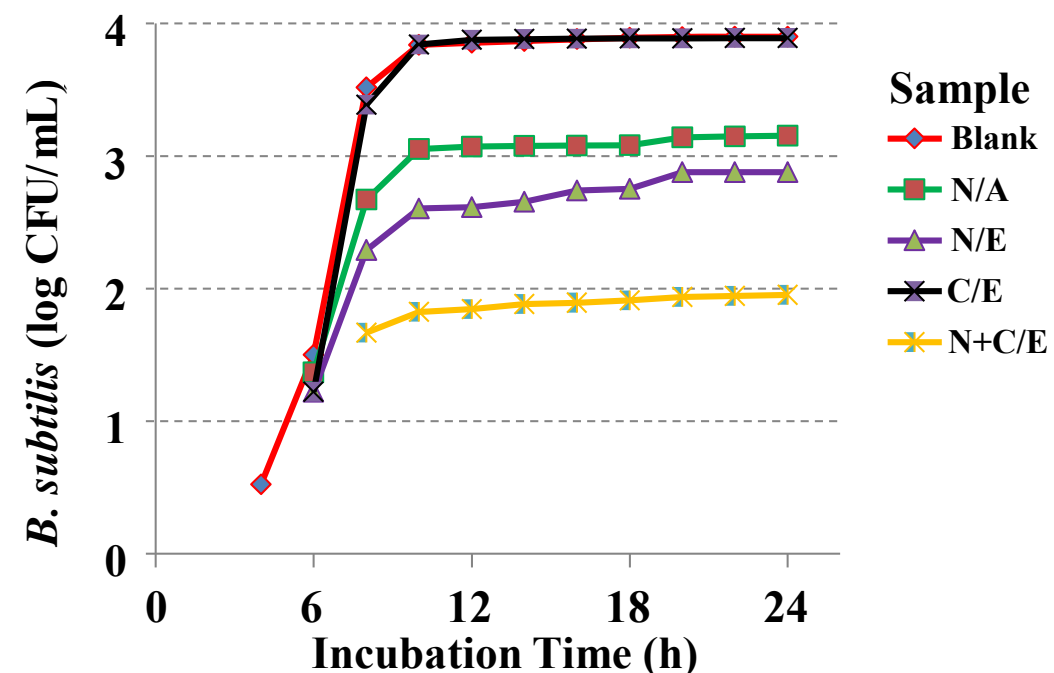

Fig. 7 B. subtilis growth upon treatment with different antimicrobial compounds, in aqueous solution or formulated into O/W nanoemulsions. Treatments: Blank (phosphate buffer); N/A: Nisin in aqueous solution; N/E: Nisin in emulsion; C/E: Carvacrol emulsion; $\mathrm{N}+\mathrm{C} / \mathrm{E}$ : Nisin combined with carvacrol in emulsion. The microbial experiments were conducted up to 24 $\mathrm{h}$ incubation at $37^{\circ} \mathrm{C}$.

The combination of nisin (dissolved in the aqueous phase) and carvacrol (dissolved in the oil phase) into $\mathrm{O} / \mathrm{W}$ nanoemulsions resulted in the most effective antimicrobial activity against spores of $B$. subtilis, as indicated in Fig. 7. Images of B. subtilis colonies grown after $24 \mathrm{~h}$ incubation at $37{ }^{\circ} \mathrm{C}$ are depicted in Fig. 8, clearly showing that the most effective treatment to inhibit $B$. subtilis growth was to formulate both antimicrobial compounds (nisin and carvacrol) simultaneously into $\mathrm{O} / \mathrm{W}$ nanoemulsion, but the synergistic mechanism has not yet been fully understood [11]. The mode of action boosting nisin antimicrobial activity appears to be related to its interactions with phospholipids in the cytoplasmic membrane of bacteria cells, and the formation of pores on the membrane, resulting in the rapid leakage of essential cytoplasmic components [7, 25]. Nisin has shown to be effective against a wide range of Gram-positive bacteria, including many important foodborne pathogens such as Listeria monocytogenes, Staphylococcus aureus, Bacillus cereus, and Clostridium botulinum [1]. Equally important, it inhibits the outgrowth of spores from several Bacillus and Clostridium species [10]. However, nisin shows little or no activity against Gram-negative bacteria [4]. In fact, this specificity of nisin towards suppressing the growth of Gram-positive bacteria is reportedly owing to fact that the cytoplasmic membrane is the target for nisin in vegetative cells and can thus explain such difference in activity. Unlike Gram-positive bacteria, Gram-negative species are covered and protected by the presence of an outer membrane carpeted by the lipopolysaccharide layer that acts as a barrier to the action of nisin on the cytoplasmic wall [10]. Otherwise, Gram-positive bacteria have relative higher concentrations of anionic lipid in their cytoplasmic membrane, facilitating nisin insertion, as compared to Gram-negative species [26].

Therefore, there is a considerable interest in using nisin in combination with other antimicrobials and treatments to expand its spectrum of activity. Combining nisin with carvacrol resulted in an increased reduction in the viable count of $B$. cereus and $L$. monocytogenes, indicating synergy between those two compounds [24]. Similarly, Gram-negative bacteria can be sensitized to nisin by exposure to chelating agents, sub-lethal heat, and to freezing [4]. 

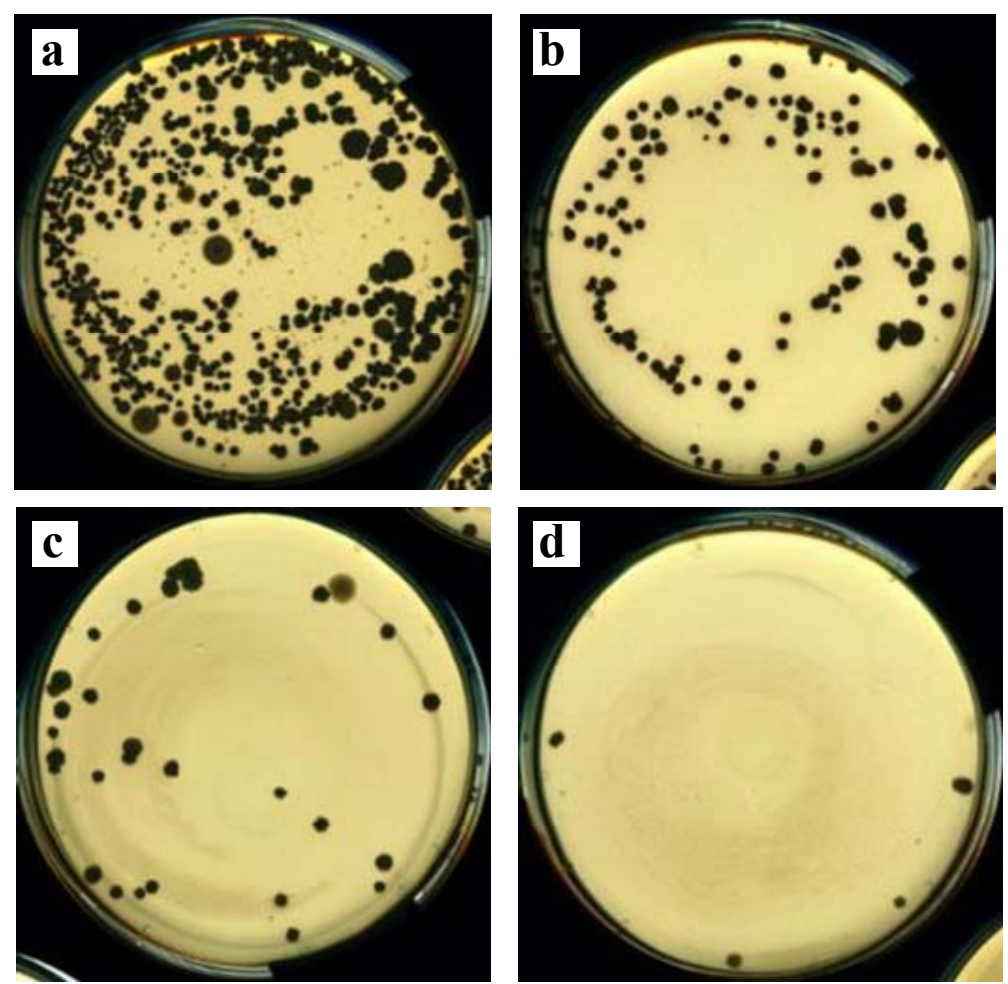

Fig. 8 B. subtilis colonies grown after $24 \mathrm{~h}$ incubation, upon treatment with different antimicrobial compounds, as follows: (a) Blank (no antimicrobial); (b) Nisin in aqueous solution: (c) Nisin in $\mathrm{O} / \mathrm{W}$ emulsion; (d) Nisin and carvacrol in emulsion. This picture shows clearly that formulating both antimicrobial compounds simultaneously into $\mathrm{O} / \mathrm{W}$ nanoemulsion was the most effective treatment to inhibit $B$. subtilis growth.

Regarding to the size of the structures involved in this study, Bacillus subtilis produces nearly $1 \mu \mathrm{m}$ sized spores when challenged by stresses such as starvation [27]. In this work, $\mathrm{O} / \mathrm{W}$ nanoemulsion loaded with the antimicrobial compounds nisin and carvacrol, in the aqueous and lipid phases respectively, resulted in droplets with a Sauter mean diameter $\left(d_{3,2}\right)$ of around $115 \mathrm{~nm}$, whereas the emulsion droplets are comparably smaller than the expected size of spores produced by $B$. subtilis. These results suggest that this difference in size may lead the way for nano-size encapsulated nisin to break through the cytoplasmic wall, so that leading to the formation of pores along the bacterial membrane, and eventual cell death. On this regard, in a future outlook the authors might perform an extensive study related to the effect of emulsion droplet size on antimicrobial activity of encapsulated nisin and carvacrol, foreseeing a better understanding over their mode of action as antimicrobial, whether those compounds are formulated into $\mathrm{O} / \mathrm{W}$ emulsions isolatedly or combined.

\section{Conclusions}

In this study, $\mathrm{O} / \mathrm{W}$ nanoemulsions loaded with antimicrobial compounds having different characteristics, namely nisin a hydrophilic compound, and carvacrol a hydrophobic compound, having mean droplet diameter of around $120 \mathrm{~nm}$ could be formulated successfully.

As demonstrated herein, the emulsions prepared had a considerably high thermal stability, whereas the mean droplet size remained unchanged even upon heating up to $50{ }^{\circ} \mathrm{C}$ for $30 \mathrm{~min}$, and stored afterwards at room temperature for 1 week.

The enhanced antimicrobial activity described in this writing relies on the synergistic combination of a hydrophilic and a hydrophobic antimicrobial 
compound, and their mode of action is likely involved with several targets in the bacterial cell, whereas it may be related to electrostatic interaction between nisin and bacteria membrane, or pore formation in the bacteria cell wall by the action of nisin. Nevertheless, in order to better understand the mechanism behind nisin and carvacrol mode of action, whether isolatedly or in a combined form, which presented advantages over these two separated assets, the effect of emulsion droplet size on antimicrobial activity remains to be elucidated.

The insights of enhancing the activity of natural antimicrobial compounds revealed here could contribute to the advancement of food industry from the safety point of view, envisaging the reduced use of chemical preservatives.

\section{Acknowledgements}

This study was partially supported by the Japan Society for the Promotion of Science KAKENHI Grant Number 15K07452, Japan. The financial support is greatly appreciated. The author Marcos A. Neves is thankful to the Program to Disseminate Tenure Tracking System, University of Tsukuba, Japan, for the partial support to this research.

\section{References}

[1] Karam, L., Jama, C., Dhulster, P., and Chihib, N. E. 2013. "Study of Surface Interactions between Peptides, Materials and Bacteria for Setting up Antimicrobial Surfaces and Active Food Packaging." Journal of Materials and Environmental Science 4: 798-821.

[2] Neves, M. A., Hashemi, J., and Prentice, C. 2015. "Development of Novel Bioactives Delivery Systems by Micro/Nanotechnology." Current Opinion in Food Science 1: 7-12.

[3] Quintavalla, S., and Vicini, L. 2002. "Antimicrobial Food Packaging in Meat Industry.” Meat Science 62: 373.

[4] Delves-Broughton, J., Blackburn, P., Evans, R. J., and Hugenholtz, J. 1996. "Applications of the Bacteriocin, Nisin.” Antonie van Leeuwenhoek 69: 193.

[5] Chang, Y., McLandsborough, L., and McClements, D. J. 2012. "Physical Properties and Antimicrobial Efficacy of Thyme Oil Nanoemulsions: Influence of Ripening Inhibitors." Journal of Agricultural and Food Chemistry
60: 12056-63.

[6] Burt, S. 2004. "Essential Oils: Their Antibacterial Properties and Potential Applications in Foods-A Review." International Journal of Food Microbiology 94: 223-53.

[7] Ji, S., Lu, J., Liu, Z., Srivastava, D., Song, A., Liu, Y., and Lee, I. 2014. "Dynamic Encapsulation of Hydrophilic Nisin in Hydrophobic Poly (Lactic Acid) Particles with Controlled Morphology by a Single Emulsion Process." Journal of Colloid and Interface Science 423: 85-93.

[8] Mattick, A. T. R., and Hirsch, A. 1947. "Further Observations on an Inhibitory Substance (nisin) from Lactic Streptococci.” The Lancet 2: 5-8.

[9] Lohans, C. T., and Vederas, J. C. 2014. "Structural Characterization of Thioether-Bridged Bacteriocins." The Journal of Antibiotics 67: 23-30.

[10] De Arauz, L. J., Jozala, A. F., Mazzola, P. G., and Penna, T. C. V. 2009. "Nisin Biotechnological Production and Application: A Review." Trends in Food Science \& Technology 20: 146-54.

[11] Ung, P., Uemura, K., Kobayashi, I., Nakajima, M., and Neves, M. A. 2014. "Formulation and Stability Evaluation of Antimicrobial-Loaded O/W Nanoemulsions." In Japan Soc. Food Eng., Annual Meeting, Tsukuba. Proceedings, 1P5P-23, 101.

[12] Hennig D., Schubert S., Dargatz, H., Kostenis, E., Fahr, A., Schubert, U. S., Heinzel, T., and Imhof, D. 2014. "Novel Insights into Appropriate Encapsulation Methods for Bioactive Compounds into Polymers: A Study with Peptides and HDAC Inhibitors." Macromolecular Bioscience 14: 69-80.

[13] Neves, M. A., Kobayashi, I., Ribeiro, H. S., and Fujiu, K. B. 2013. "Encapsulation of Bioactive Compounds into Micro- /Sub-Micron Sized Dispersions Using Microchannel Emulsification or High-Pressure Homogenization.” In Bionanotechnology. Oxford, UK: Wiley \& Sons Inc., 605-18.

[14] Neves, M. A., Wang, Z., Kobayashi, I., and Nakajima, M. 2014. "From Natural Resources to Bioactives Delivery Systems." Sustainable North African Society. Nova Science Publishers: New York, 103-16.

[15] Neves, M. A., Wang, Z., Kobayashi, I., and Nakajima, M. 2015. "Assessment of Oxidative Stability in Fish Oil-in-Water Emulsions: Effect of Emulsification Process, Droplet Size and Storage Temperature." Journal of Food Process Engineering, in press. DOI: 10.1111/jfpe. 12316 .

[16] Neves, M. A., Ribeiro, H. S., Fujiu, K., Kobayashi, I., and Nakajima, M. 2008. "Formulation of Controlled Size PUFA-Loaded Oil-in-Water Emulsions by Microchannel Emulsification Using Beta-carotene Rich Palm Oil." Industrial \& Engineering Chemistry Research 47: 
6405-11.

[17] Nakamura, L. K., Roberts, M. S., and Cohan, F. M. 1999. "Relationship of Bacillus Subtilis Clades Associated with Strains 168 and W23: A Proposal for Bacillus Subtilis Subsp. Subtilis Subsp. nov. and Bacillus Subtilis Subsp. Spizizenii Subsp. nov." International Journal of Systematic Bacteriology 49: 1211-5.

[18] Bani-Jaber A., Mcguire J., Ayres J. W., and Daeschel M. A. 2000. "Efficacy of the Antimicrobial Peptide Nisin in Emulsifying Oil in Water." Food Engineering and Physical Properties 65: 502-6.

[19] Andreas, J. M., Hauser, E. A., and Tucker, W. B. 1938. "Boundary Tension by Pendant Drops." Journal of Physical Chemistry 42: 1001-19.

[20] Periago, P. M., and Moezelaar, R. 2001. "Combined Effect of Nisin and Carvacrol at Different $\mathrm{pH}$ and Temperature Levels on the Viability of Different Strains of Bacillus Cereus." International Journal of Food Microbiology 68: 141-8.

[21] Yang, Y., Leser, M. E., Sher, A. A., and McClements, D. J. 2013. "Formation and Stability of Emulsions Using a
Natural Small Molecule Surfactant: Quillaja Saponin (Q-Naturale ${ }^{\circledR}$ ).” Food Hydrocolloids 30: 589-96.

[22] Chuah, A. M., Kuroiwa, T., Kobayashi, I., and Nakajima, M. 2009. "Effect of Chitosan on the Stability And Properties of Modified Lecithin Stabilized Oil-in-Water Monodisperse Emulsion Prepared by Microchannel Emulsification." Food Hydrocolloids 23: 600-10.

[23] Han, J. H. 2000. “Antimicrobial Food Packaging.” Food Technology 54: 56-65.

[24] Pol, I. E., and Smid, E. J. 1999. "Combined Action of Nisin and Carvacrol on Bacillus Cereus and Listeria Monocytogenes." Letters in Applied Microbiology 29: 166-170.

[25] DRIKS, A. 1999. "Bacillus subtilis Spore Coat." Microbiology and Molecular Biology Reviews 63: 1-20.

[26] Breukink, E., and Kruijff, B. 1999. "The Lantibiotic Nisin, a Special Case or Not?" Biochimica et Biophysica Acta-Biomembranes 1462: 223-34.

[27] Carrera M., Zandomeni, R. O., Fitzgibbon, J., and Sagripanti, J. L. 2007. "Spore Sizes of Bacillus Species." Journal of Applied Microbiology 102: 303-12. 